\title{
A CONSOLIDAÇÃO POLÍTICA DA FAMÍLIA STRAPASSON NO MUNICÍPIO DE COLOMBO
}

\author{
Cecilia Pagnozzi do Nascimento ${ }^{1}$ \\ Matheus Fortunato Dário ${ }^{2}$
}

\begin{abstract}
RESUMO: Colombo, município localizado no interior do estado do Paraná, ocupado inicialmente por famílias oriundas da imigração italiana, é uma cidade constituída por meio de tradições familiares. Sendo, até os dias de hoje, dominada e influenciada por algumas famílias, as quais ocupam exclusivamente o poder há muitos anos. Entre elas, este artigo tem como objetivo abordar a trajetória política da Família Strapasson, traçando a sua genealogia e períodos de atuação na Câmara Municipal de Colombo, assim como, os escândalos que permeiam esse jogo político. Estabelecendo assim, a forte relação que essa família possui com o Estado e a economia do munícipio.
\end{abstract}

PALAVRAS-CHAVES: Colombo; Strapasson; Estado; Relações de poder.

\section{THE POLITICAL CONSOLIDATION OF THE STRAPASSON FAMILY IN THE MUNICIPALITY OF COLOMBO}

\begin{abstract}
Colombo is a county located in the backwoods of the state of Paraná, occupied initially by families that came from Italy. It's a city made of familiar traditions. It still being dominated and influenced by some particular families, which occupy exclusively the power since many years ago. Among them, this article intends to show the Strapasson's Family politic path, tracking down their genealogy and periods of operation in the Town Hall of Colombo. As the scandals that surround this political game. Thus establishing the strong relation between this Family and the State and Economy of Colombo.
\end{abstract}

KEYWORDS: Colombo; Strapasson; State; Power relationships.

\section{Introdução}

A consolidação política do município de Colombo, ocorreu em novembro de 1877, quando um grupo de imigrantes italianos, compostos de: 162 colonos: 48 homens, 42 mulheres, 42 meninos e 30 meninas chefiados pelo Padre Angelo Cavalli, saíram do Norte

\footnotetext{
${ }^{1}$ Graduanda no Curso de Engenharia Elétrica, Universidade Tecnológica Federal do Paraná, UTFPR.

Contato: cecilia.pagnozzi@ hotmail.com

${ }^{2}$ Graduando no Curso de Engenharia Elétrica, Universidade Tecnológica Federal do Paraná, UTFPR.

Contato: matheusdario@aluno.utfpr.edu.br
} 
da Itália, região do Veneto, como Nove, Cismon del Grapa, Maróstica, Bassano del Grapa, Valstagna, entre outras famílias e chegaram às terras do Paraná. Primeiramente, esses imigrantes se estabeleceram em Morretes na Colônia Nova Itália e mais tarde, abandonaram as terras e subiram a Serra do Mar, em direção a Curitiba. (PREFEITURA, 2013).

Em 1889, o Brasil torna-se República e, no ano seguinte, a Colônia de Colombo emancipa-se, desmembrando-se da capital paranaense, Curitiba. Em 5 de fevereiro de 1890, a colônia torna-se o município de Colombo. Na mesma data, instalaram-se no novo município a Intendência Municipal, primeiro órgão regente de Colombo, e a Câmara Municipal, pois ambos estavam localizados em um grupo escolar. (PREFEITURA, 2013).

Francisco de Camargo Pinto ${ }^{3}$ foi o primeiro a presidir o Legislativo colombense, entre 1890 e 1891, onde João Gualberto Bittencourt ${ }^{4}$ foi o primeiro presidente eleito para a primeira Câmara Municipal, em pleito de 21 de abril de 1892, com outros sete camaristas. A segunda sede da Câmara de Colombo foi a casa do pioneiro José Marcelino da Rose, na Rua Marques Guimarães, antes chamada de Rua 5 de Fevereiro (PREFEITURA, 2013).

Em 1894, os trabalhos do Executivo e do Legislativo foram transferidos, por questões políticas, para uma das casas do engenheiro Francisco Camargo Pinto, que já cedia uma de suas instalações para servir de quartel. Já no século XX, os poderes Legislativo e Executivo colombenses contam mais uma vez com o apoio de um de seus cidadãos para seguir seus trabalhos: Ângelo Lazzarotto, quem oferece sua residência como sede dos dois poderes. (PREFEITURA, 2013).

Em 1917, a Câmara ganha sua primeira "casa própria”, quando o então presidente do Legislativo, José Leal Fontoura ${ }^{5}$, informou a compra de casa e terreno na Rua da Praça da República. Em 1930, nova mudança, para um edifício de alvenaria, com traços arquitetônicos tipicamente italianos construído durante a administração do prefeito Carlos Fontoura Falavinha ${ }^{6}$. O local abriga, atualmente, a Casa de Cultura do município, na Rua

\footnotetext{
${ }^{3}$ Engenheiro, proprietário de lotes, emprestou uma de suas instalações para discussão de trabalhos legislativos e executivos de Colombo, no ano de 1894. (GUIA DE COLOMBO, 2019).

${ }^{4}$ Em 1891, foi Intendente Colombo (atual cargo de Prefeito), ex-colônia Alfredo Chaves, no Paraná, e o primeiro presidente da Câmara Municipal de Colombo, eleito em 21 de abril de 1892. (MEMÓRIA POLÍTICA, 2019)

${ }^{5}$ Presidente do Legislativo de Colombo. No dia 10 de abril de 1917, o Sr. José Leal Fontoura, presidente da Câmara, cientifica aos Camaristas a compra das casas e terreno do Sr. Venâncio Trevisan, sito à Praça da República, nesta Vila, para propriedade da Câmara Municipal de Colombo (CÂMARA COLOMBO, 2019). Umas principais ruas do Centro de Colombo, leva seu nome, próxima à Prefeitura. (Google Maps, 2019).

${ }^{6}$ Prefeito de Colombo, durante seu mandato inaugurou a sexta sede da Câmara Municipal de Colombo em 1930. A partir do ano de 1983, devido à construção do Paço Municipal, a sede passou a abrigar a Biblioteca
} 
Quinze de Novembro. A atual sede da Câmara foi inaugurada em 27 de janeiro de 1983, na Rua Francisco Busato. O edifício foi reformado e reinaugurado em 10 de dezembro de 1998. (PREFEITURA, 2013).

O município de Colombo não é uma exceção na forte tradição brasileira de envolver a família no campo político e perpetuar essa influência ao longo de décadas, até séculos, como relata Grill (2004; p.159):

Existem algumas elites tradicionais que conseguem se adaptar às mudanças e inconstâncias políticas e ao mesmo tempo são capazes de reforçar o seu poder sob determinada região. Como é o caso da família Strapasson.

Para fundamentar essa discussão,

(...) ao tomar como objeto de análise os políticos descendentes de imigrantes e que formaram famílias de políticos a partir de laços com grupos tradicionais, aponta que tais grupos possuem trajetórias marcadas por momentos de afirmação, sucessão, distinção e de aproximação inscritos na lógica política de conflito, ruptura e adesões. (GOULART et.al), 2017, p. 190)

Entender a consolidação de certas famílias no aparelho Estado não é uma tarefa fácil, é tudo muito bem calculado e executado, seguindo um jogo político de alta racionalidade. No que diz respeito à importância das famílias e suas ações, Grill (2012, p. 139) expõe: “(...)constituem o locus de reprodução, pois são capazes de orquestrar um conjunto de estratégias.” Afinal,

Conjunto de estratégias que formam um sistema de funções interdependentes, compensatórias e cronologicamente articuladas." É nesse sentido que se constitui como positivo o pertencimento aos grupos de famílias políticas, porque a relação com certos sobrenomes acarreta crédito eleitoral e, em certa medida, torna-se fator preponderante no campo de disputa e de escolha por parte do eleitor. (GOULART et al., 2017, p.192)

É importante ressaltar que a realização desta pesquisa bibliográfica foi realizada a partir de uma coleta de dados baseada no estudo do assunto da consolidação política do

Pública Municipal da Sede, o Arquivo da Prefeitura e a Câmara Municipal. Após cinco anos, com a construção de um novo espaço para a Câmara, o edifício passou a funcionar como Agência do extinto Banco Banestado, Arquivo da Prefeitura e a Casa da Cultura / Departamento de Cultura. (BIBLIOTECA IBGE, 2019). 
Revista NEP - Núcleo de Estudos Paranaenses, Curitiba, v.5, n.1, jun. 2019

município de Colombo baseada em livros, periódicos científicos e artigos encontrados na Hemeroteca, assim como, dados do TRE de Colombo e da Câmara Municipal de Colombo.

A definição de pesquisa bibliográfica, conforme o autor Antônio Carlos Gil (2009), pode-se definir como: procedimento racional e sistemático que tem como objetivo proporcionar respostas aos problemas que são propostos. A pesquisa é requerida quando não se dispõe de informação suficiente para responder ao problema, ou então quando a informação disponível se encontra em tal estado de desordem que não possa ser adequadamente relacionada ao problema.

A pesquisa é desenvolvida mediante o concurso dos conhecimentos disponíveis e a utilização cuidadosa de métodos, técnicas e outros procedimentos científicos. Após a seleção dos materiais (livros, artigos) pertinente ao assunto, estes foram organizados e analisados conforme a ordem cronológica do estudo.

\section{Família Strapasson}

A literatura menciona a genealogia da família Strapasson em Colombo, podendo ser traçada partindo-se de um membro chamado Marco Strapazzon, nascido em 01 de julho de 1854, em San Vito de Arsiè, Itália que faleceu em Colombo, Paraná, em 10 de julho de 1919. Marco embarcou em um navio chamado Pampa em Gênova e chegou ao Brail em 30 de abril de 1880, com sua esposa Maria Angela Strapazzon. Primeiramente estabeleceram-se na Colônia Nova Itália, em Morretes, região litorânea no Paraná, e após fixaram residência na Colônia Faria, em Colombo - PR. Assim, iniciou-se a genealogia dos Strapasson no município de Colombo. A imagem a seguir revela o lote de terra comprado por Marco na região de Colombo. 
Revista NEP - Núcleo de Estudos Paranaenses, Curitiba, v.5, n.1, jun. 2019

Figura 1: Planta do núcleo Presidente Faria, Colombo, Paraná.

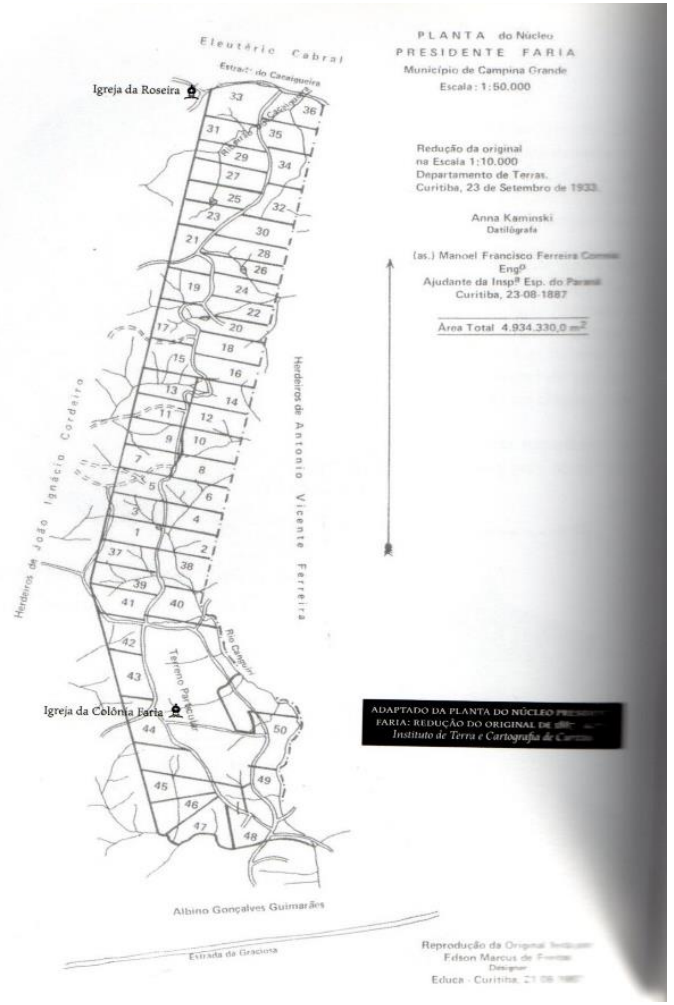

Fonte: TORQUES, Caio Vinícius. Imbuial e Roseira,2013.

Figura 2: Proprietários de terra da região de Colombo. 
Revista NEP - Núcleo de Estudos Paranaenses, Curitiba, v.5, n.1, jun. 2019

\begin{tabular}{|c|c|c|}
\hline LOTE & PROPRIETÁRIO(S) & DATA DE QUITAÇÃO \\
\hline 1 & Francisco Coradin & 6 de maio de 1895 \\
\hline 2 & Antonio Ruzenente & 14 de maio de 1895 \\
\hline 3 & João Pontarolla & 6 de maio de 1895 \\
\hline 4 & Carlos Henemann & 3 de novembro de 1896 \\
\hline 5 & Pedro Pontarolla & 12 de agosto de 1897 \\
\hline 6 & Carlos Henemann & 3 de novembro de 1896 \\
\hline 7 & Angelo Pontarolla & 26 de agosto de 1896 \\
\hline 8 & Carlos Henemann & 3 de novembro de 1896 \\
\hline 9 & Antonio Fracaro & 26 de agosto de 1898 \\
\hline 10 & Carlos Henemann & 3 de novembro de 1896 \\
\hline u & Joâo Coradin Filho & 6 de maio de 1895 \\
\hline 12 & Pedro Pontarolla & 27 de dezembro 1895 \\
\hline 13 & Valentin, Vittorio e Luiz Collere & 5 de fevereiro 1917 \\
\hline 14 & Domenico Mocellin & 28 de fevereiro 1896 \\
\hline 15 & João Collere & 4 de fevereiro 1914 \\
\hline 16 & Olympio Modesto Cardoso & 14 de novembro de 1906 \\
\hline 17 & Francisco Sforza & 10 de novembro de 1908 \\
\hline 18 & Francisco Cumin & 14 de junho de 1899 \\
\hline 19 & Aurélio Ribeiro de Campos & 5 de janeiro de 1893 \\
\hline 20 & Valentino Gheno & 13 de janeiro de 1896 \\
\hline 21 & Pietro Trevisan & 16 de maio de 1895 \\
\hline 22 & Valentino Gheno & 23 de outubro de 1897 \\
\hline 23 & Pietro Trevisan & 14 de agosto de 1897 \\
\hline 24 & Luigi Andreatta & 28 de julho de 1915 \\
\hline 25 & Luiz Schena, Henrique Henemann e João Collere F. & 17 de maio de 1916 \\
\hline 26 & Domenico Andreatta & 21 de outubro de 1893 \\
\hline 27 & Nicolau Collere & 04 de maio de 1914 \\
\hline 28 & Antonio Coradin & 26 de janeiro de 1901 \\
\hline 29 & Antonio Rozzenente & 13 de julho de 1895 \\
\hline 30 & Francisco e Antonio Coradin & 14 de setembro de 1903 \\
\hline 31 & Bortolo Schena & 5 de agosto de 1903 \\
\hline 32 & Frederico Treder & 19 de novembro de 1900 \\
\hline 33 & Bernardo Taverna & 23 de julho de 1895 \\
\hline 34 & Antonio Francisco de Barros e Francisco Sant'Anna & 17 de março de 1910 \\
\hline 35 & Ferdinando, Antonio, Rosário e Pedro Schena & 29 de outubro de 1918 \\
\hline 36 & Bernardo Taverna & 23 de julho de 1895 \\
\hline 37 & Antonio Coradin & 21 de agosto de 1896 \\
\hline 38 & Pedro Andreatta & 8 de maio de 1896 \\
\hline 39 & Pedro Poletto & 27 de outubro de 1894 \\
\hline 40 & Luiz Cunha e Julio Cunha & 13 de julho de 1908 \\
\hline 41 & Marco Strapazzon & 6 de junho de 1895 \\
\hline
\end{tabular}

Fonte: TORQUES, Caio Vinícius. Imbuial e Roseira, 2013

Atualmente, a Família Strapasson é conhecida por seus negócios na agricultura, nos transportes e no ramo farmacêutico, além de ter uma consolidada carreira política (CONSULTASOCIO, 2019). Visto que, José Renato Strapasson é um dos vereadores com maior tempo de casa, ao todo 19 anos no poder legislativo (PREFEITURA, 2019).

\section{Histórico político da família Strapasson}

A família Strapasson se faz presente no cenário político do município de Colombo desde muito cedo (PREFEITURA,2019). As primeiras menções sobre membros da família ocupando cargos no poder político datam da década de 20, quando Ângelo Strapasson Costa e João Strapasson Neto foram eleitos vereadores, desde então a família é presença constante no cenário eleitoral do município. 
Tal realidade se torna evidente a partir de dados obtidos através da Câmara Municipal de Colombo e do Tribunal Regional Eleitoral do Paraná, onde é possível identificar diversas menções ao sobrenome Strapasson nos registros eleitorais do município:

(...)presente no nome de torno de trinta políticos eleitos nos registros dos resultados das eleições ocorridas dos anos 1945 até 2019. Durante todo o período de 1945 até 2019 é possível observar candidatos a prefeito e vereador em todas as eleições municipais com exceção do ano de 1972. (PREFEITURA; TRE, 2019).

Os dados levantados a respeito da presença do sobrenome Strapasson nos resultados eleitorais estão ordenados na tabela 1 a seguir.

Tabela 1: Resultados Eleitorais da Família Strapasson

\begin{tabular}{|c|c|}
\hline Ano: & Candidato(s) Eleito(s): \\
\hline 1947 & Vereadores Ângelo Strapasson Neto e João Strapasson Neto, pelo Partido Social Democrático \\
\hline 1951 & Vereador Pedro Strapasson, pela União P.S.P. -PR \\
\hline 1955 & Prefeito Gabriel d'Anunzio Strapasson, Frorentino Strapasson, como vereador suplente. \\
\hline 1959 & Carlos Strapasson, como vereador suplente. \\
\hline 1963 & $\begin{array}{l}\text { Alfredo Strapasson, como suplente pela Coligação P.S.B-P.T.; Natal Fiala Strapasson, como } \\
\text { suplente pela União Democrática Nacional. }\end{array}$ \\
\hline 1968 & $\begin{array}{l}\text { Vereadores Odorico Strapasson, e Natalio Strapasson ambos pela Alinça Renovadora Nacional; } \\
\text { Alceu Ângelo Strapasson, Ozorio Strapasson ambos como suplentes pela Aliança Renovadora } \\
\text { Nacional. }\end{array}$ \\
\hline 1972 & \\
\hline 1976 & Dorico Strapasson, como suplente pelo Arena; Walfrido Strapasson, como suplente pelo M.D.B \\
\hline 1982 & Floriano Jordão Strapasson, candidatou-se pelo P.T.B., o partido não obteve quociente eleitoral. \\
\hline 1988 & Vice Prefeito Edson Luiz Strapasson; Isabelle Cristina Pavin como vereadora. \\
\hline 1992 & $\begin{array}{l}\text { Prefeito Elson Strapasson pelo PMDB; Dorico Strapasson, como suplente pelo PST; Angelo } \\
\text { Betinardi, como suplente pelo PMDB. }\end{array}$ \\
\hline 1996 & José Renato Strapasson, como vereador pelo PFL;. \\
\hline 2000 & José Renato Strapasson, como vereador pelo PPB. \\
\hline 2004 & José Nicacio Strapasson como vereador pelo PTN. \\
\hline 2008 & José Renato Strapasson, como vereador; José Nicácio Strapasson, como suplente. \\
\hline 2012 & José Renato Strapasson, Doliria Lodregue Strapasson ambos como vereadores. \\
\hline
\end{tabular}


2016 José Renato Strapasson, Doliria Lodregue Strapasson, como vereadores; Dra. Marielle Strapasson se candidataram pelo PEN.

Fonte: Os autores.

Além dos registros eleitorais obtidos através da câmara municipal do município de Colombo e do TRE-PR, também foram obtidas informações adicionais a partir do acervo da Biblioteca Nacional (HEMEROTECA, 2019). Por meio destas fontes foi possível identificar ocasiões que supostos membros se fizeram presente na vivência e no desenvolvimento de Colombo, assim como, no cenário político. Ângelo Strapasson Costa foi o primeiro membro da família que foi encontrado no registro de participação política no município de Colombo. A informações obtidas citam Ângelo como eleitor listado no município de Colombo e como integrante do Diretório Municipal de Colombo em 1945.

Figura 3: Ângelo Strapasson Costa

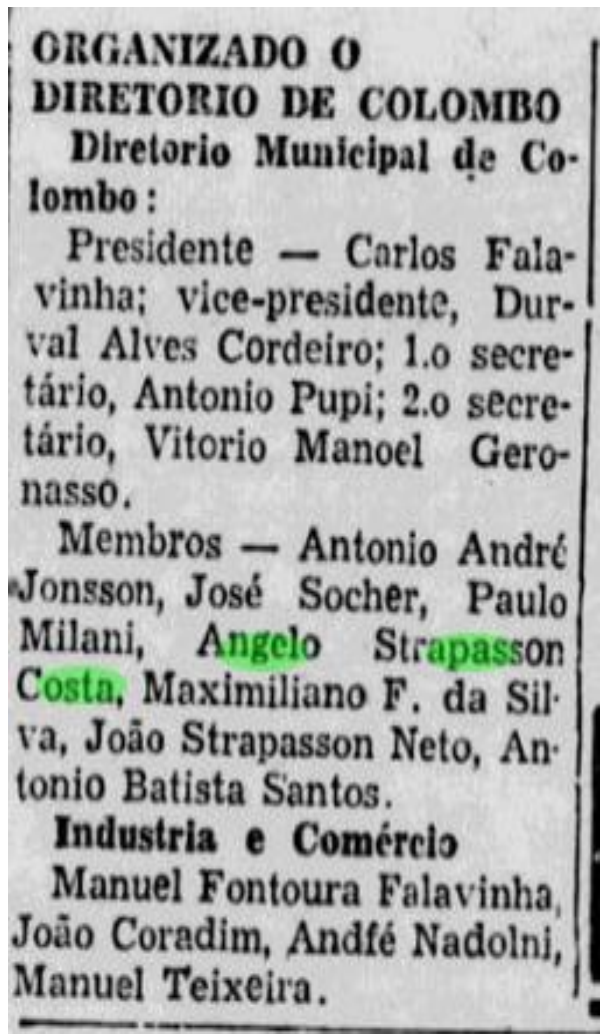

Fonte: O Dia (PR) - 1923 a 1961 - Disponível em: http://memoria.bn.br/DocReader/DocReader.aspx?bib=092932\&pesq=\%C 3\%82ngelo\%20Strapasson\%20Costa 
Também existem registros da participação do mesmo na câmara dos vereadores como vereador de Colombo.

Figura 4: Vereador Angelo Strapasson Costa

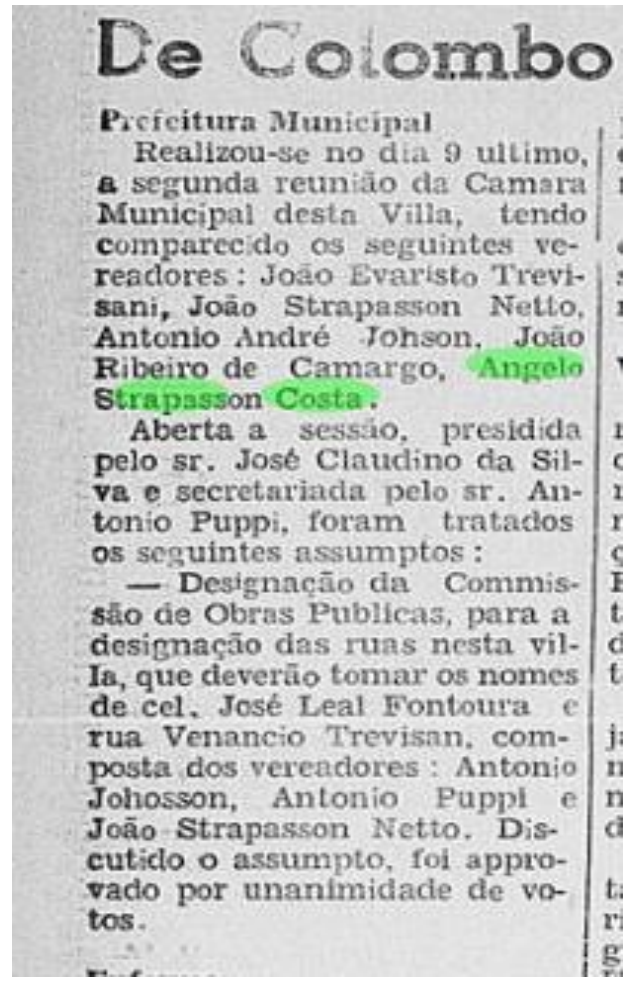

Fonte: O Estado (PR) - 1936 a 1938 -Disponível em:

<http://memoria.bn.br/DocReader/DocReader.aspx?bib=830275\&pesq=\%C3\%82ngelo\%20Strapass on\%20Costa>. Acesso em: 12 abr. 2019.

Segundo os registros da câmara municipal de Colombo, Ângelo Strapasson Costa exerceu mandato como vereador nos anos de 1917 a 1920 e 1947 a 1951, porém não é possível confirmar que a pessoa que exerceu ambos os mandatos seja a mesma, pois o nome Ângelo é extremamente comum na família Strapasson. Os dados disponíveis levam a supor que o Ângelo Strapasson que exerceu o cargo em 1917 se trata do Ângelo Strapasson nascido em 1865 na Itália, filho de Marco e Maria Angela Strappazzon. Já o mandato exercido de 1947 a 1951 é possível atribuir a Ângelo Strapasson. 
Revista NEP - Núcleo de Estudos Paranaenses, Curitiba, v.5, n.1, jun. 2019

Foi possível obter informações sobre João Strapasson Neto referentes a dívidas existentes em seus nomes, conforme mostrado na figura 5.

Figura 5: João Strapasson Neto citado no pagamento do tesouro do Estado.

\section{PAGAMENTOS NO TESOURO DO ESTADO}

Pagamentos autorizados pelo st. di. secretario da Fa. zendia, por intermidio das Recebedorias e Coletorias do lis. terior, conforme relaço abaizo,

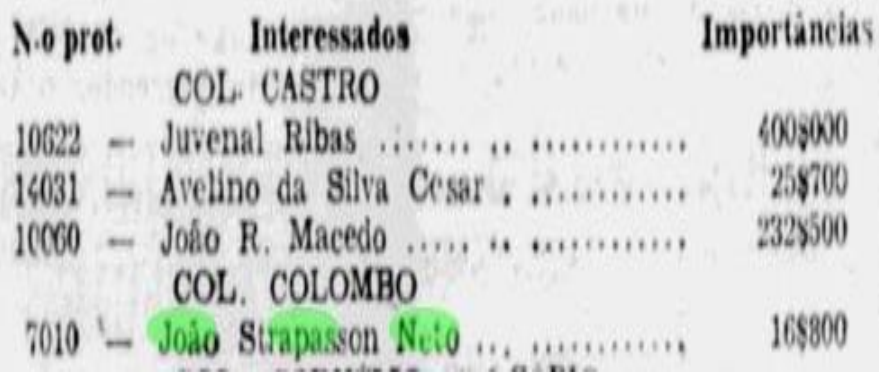

Fonte: O Dia (PR) - 1923 a 1961 - DocReader Web.

$<$ http://memoria.bn.br/DocReader/DocReader.aspx?bib=092932\&pesq=Jo\%C3\%A3o\%20Strapasson\%20Net o>>. Acesso em: 15 abr. 2019.

Observam-se registros da participação de João Strapasson Neto no Diretório municipal de Colombo, onde participou da instituição como secretário. Primeiramente ele é citado na fundação do diretório e posteriormente na reconstrução do mesmo. Também existem registros de um caso de corrupção atribuído ao vereador José Nicácio Strapasson. 
Figura 6: João Strapasson Neto é citado como um membro do Diretório de Colombo.

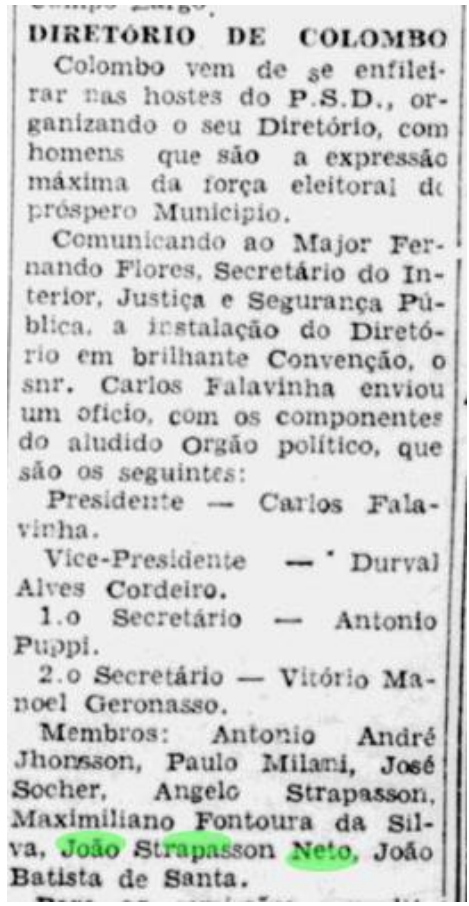

Fonte: O Dia (PR) - 1923 a 1961 - DocReader Web.

Disponível em:

<http://memoria.bn.br/DocReader/DocReader.aspx?bib=092932\&pesq=Jo\%C3\%A3o\%20Strapasson\%20Net o >. Acesso em: 12 abr. 2019.

A fim de verificar se existe relação de parentesco entre os vereadores e prefeitos eleitos em Colombo com o sobrenome Strapasson foram obtidos alguns dados a respeito da genealogia da família. A partir das informações identifica-se uma possível relação de parentesco, considerando apenas alguns poucos dentre os citados nos registros eleitorais graças a dados obtidos por meio do site da família Strapasson. Essa realidade se deve ao fato de, com o passar dos anos, os ramos familiares foram se distanciando e o número de integrantes da família foi aumentando de forma que a obtenção de dados foi bastante dificultada.

Ainda assim, foi possível determinar uma suposta relação de parentesco entre alguns dos membros da família que marcaram presença na política: Ângelo Strapasson Costa, João Strapasson Neto, Pedro Strapasson, Alfredo Strapasson, Gabriel d'Anunzio Strapasson e Dorico Strapasson. Segue os dados obtido em forma de árvore genealógica. 
Revista NEP - Núcleo de Estudos Paranaenses, Curitiba, v.5, n.1, jun. 2019

Figura 7: Segmento da árvore genealógica da família Strapssson.

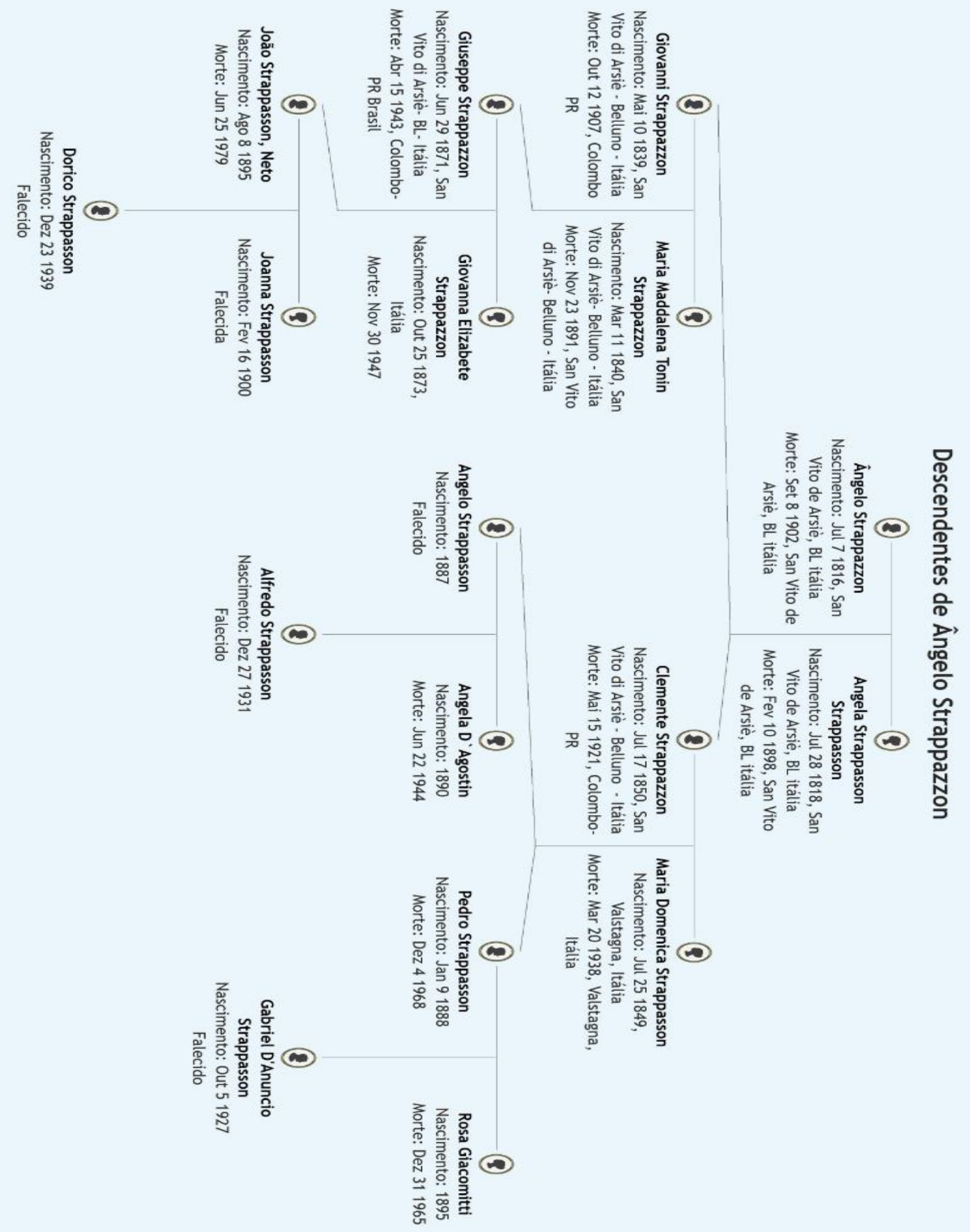

Fonte:

$<$ http://memoria.bn.br/DocReader/DocReader.aspx?bib=830275\&pesq=\%C3\%82ngelo\%20Strapasson $\% 20 \mathrm{C}$ osta>. Acesso em: 12 abr. 2019. 
Revista NEP - Núcleo de Estudos Paranaenses, Curitiba, v.5, n.1, jun. 2019

Um caso especial é o político José Renato Strapasson, só como vereador ele tem 19 anos acumulados de mandatos. Valendo ressaltar que este tem um patrimônio acumulado de R\$ 3.802.800,00, além de ser sócio de 13 empresas no estado do Paraná. (CONSULTASOCIO, 2019). Como qualquer bom político no Brasil, José não conseguiu escapar dos escândalos políticos. Por exemplo, “A Justiça determinou que a Prefeitura de Colombo, na Região Metropolitana de Curitiba (RMC), deve exonerar 14 funcionários que são parentes de vereadores ou de assessores da administração municipal. A ação movida pelo Ministério Público (MP) por nepotismo envolve filhos, pais, sobrinhos, tios e cunhados de políticos e funcionários públicos da cidade. A investigação do MP começou após reportagem da RPC TV mostrar que o presidente da Câmara José Renato Strapasson (PTB), conhecido como Pelé, contratou mais de 12 parentes para a sua administração. O vereador foi prefeito interino da cidade durante o começo do mandato, e chegou a afirmar na época que não via problemas em contratar parentes". (PARANÁ, RPC, 2014)

\section{Conclusão}

A partir de todos os dados levantados, é possível afirmar sem sombra de dúvidas que o município de Colombo está intimamente relacionado à uma configuração de famílias tradicionais ocupando o espaço público.

Analisando a participação política dos membros família Strapasson nas eleições anteriores e comparando com a descendência encontrada podemos afirmar que esse grupo se encontra no poder desde 1917 e, segundo os dados sugerem tal vínculo consanguíneo junto ao poder político se perpetua até a atualidade.

Um aspecto interessante de salientar, é o Diretório Político do Município de Colombo, que funcionava como uma organização composta de membros com grande expressão eleitoral. Fator decisivo para a eleição. Fazer parte deste Diretório, mesmo se o candidato não fosse eleito, já era uma grande prova da sua influência eleitoral.

Analisando os dados levantados, concluiu-se a importância da tradição familiar no município. O grupo Strapasson só conseguiu ter essa enorme expressão política usando sua história a favor. Como Colombo é um município formado por imigrantes italianos, nada mais comum e lógico, que uma família italiana ocupasse o poder. A tradição conta uma história e 
pesa na hora da população votar. O povo acaba se identificando com os mesmos valores conservadores que a família passa, tendo em vista os partidos políticos dos Strapasson. Ou seja, em sua maioria, partidos que defendiam e ainda defendem o conservadorismo. Marca nas propagandas políticas de Colombo.

Portanto, Colombo não escapa das estatísticas, visto que também é um município dominado por famílias. E, o clã Strapasson não se livra dos clichês políticos que as famílias tradicionais acabam passando ao longo das décadas para se manterem no poder, entre eles, casamentos, nepotismo, alianças políticas. Enfim, tudo faz parte de um grande jogo político, muito bem calculado.

\section{Referências Bibliográficas/ Obras Consultadas}

BIBLIOTECA IBGE. Disponível em: <https://biblioteca.ibge.gov.br/index.php/bibliotecacatalogo?view=detalhes\&id=443783>. Acesso em: 27 jun. 2019.

BRASIL247.Disponível em:<http://http://www.brasil247.com>. Acesso em: 08 jun. 2019.

CÂMARA

COLOMBO.

Disponível

em:

<http://www.camaracolombo.pr.gov.br/historico.htm >. Acesso em 27 de junho de 2019.

CONSULTASOCIO. Disponível em: <https://www.consultasocio.com/q/sa/jose-renatostrapasson>. Acesso em: 07 jun. 2019.

DIRETÓRIODECOLOMBO.Disponívelem:<http://memoria.bn.br/DocReader/DocReader. aspx $?$ bib $=092932 \&$ pesq $=\%$ C3\% 82ngelo\%20Strapasson $\% 20$ Costa $>$. Acesso em: 08 jun. 2019.

ESMAELMORAIS. Disponível:<http://http://www.esmaelmorais.com.br>. Acesso em: 08 jun. 2019.

GIL, A.C. Como elaborar projetos de pesquisas. Editora Atlas. 2009. 4.ed.

GRILL, I. G. "As Bases das Heranças Políticas no Rio Grande do Sul: parentesco, partidos e redes". Sociedade em Debate, v. 10, n. 2, 2004.

GRILL, Igor G. “ 'Famílias', ascensão social e alinhamentos partidários no Rio Grande do Sul”. Revista de Ciências Sociais, v. 43, n. 2, 2012.

GRILL, Igor G. Parentesco, Redes e Partidos: as bases das heranças políticas no Rio Grande do Sul. Tese de doutorado. Porto Alegre: Universidade Federal do Rio Grande do Sul, 2003. 
GOULART, Mônica H. H. S.; OLIVEIRA, Ricardo C. de; MONTEIRO, J. M.; VANALI, A. C. Família, parentesco, instituições e poder no Brasil: retomada e atualização de uma agenda de pesquisa. Revista Brasileira de Sociologia, v. 5, n. 11, set/dez. 2017.

GUIA DE COLOMBO. Disponível em: <http://www.guiadecolombo.com.br/empresadetalhes/camara-municipal-de-colombo >. Acesso em: 27 jun. 2019.

HEMEROTECA. Disponível em: <https://bndigital.bn.gov.br/hemeroteca-digital/>. Acesso em: 06 jun. 2019.

MEMÓRIAPOLÍTICA.Disponívelem:<http://memoriapolitica.alesc.sc.gov.br/biografia/45 5-Joao_Gualberto_Bittencourt >. Acesso em: 27 jun. 2019.

PARANÁ RPC. Disponível em: <http://g1.globo.com/pr/parana/noticia/2014/04/justicamanda-prefeitura-de-colombo-demitir-14-pessoas-por-nepotismo.html>. Acesso em: 08 jun. 2019.

PORTALSTRAPASSON. Disponível em: 〈http://http://www.portalstrapazzon.cgst.com>. Acesso em: 08 jun. de 2019.

PREFEITURA. Disponível em: 〈http:// http://www.colombo.pr.gov.br〉. Acesso em: 27 jun. 2019.

STRAPASSONCOSTA.Disponívelem: <http://memoria.bn.br/DocReader/DocReader.aspx ?bib $=830275 \&$ pesq $=\%$ C3\%82ngelo\%20Strapasson \%20Cost $>$. Acesso em: 08 jun. 2019.

STRAPASSON NETO. Disponível em: <http://memoria.bn.br/DocReader/DocReader.aspx?bib=092932\&pesq=Jo\%C3\%A3o\%20 Strapasson\%20Neto>. Acesso em: 08 jun. de 2019.

TORQUES, C. V. Imbuial e Roseira, nossas famílias. Ed: Evangraf/ RS. Curitiba, 2013.

Recebido em: 30 maio 2019.

Aceito em: 24 jun. 2019. 